\title{
Indicadores de derechos humanos al agua y al saneamiento: un salto cualitativo para su cumplimiento efectivo
}
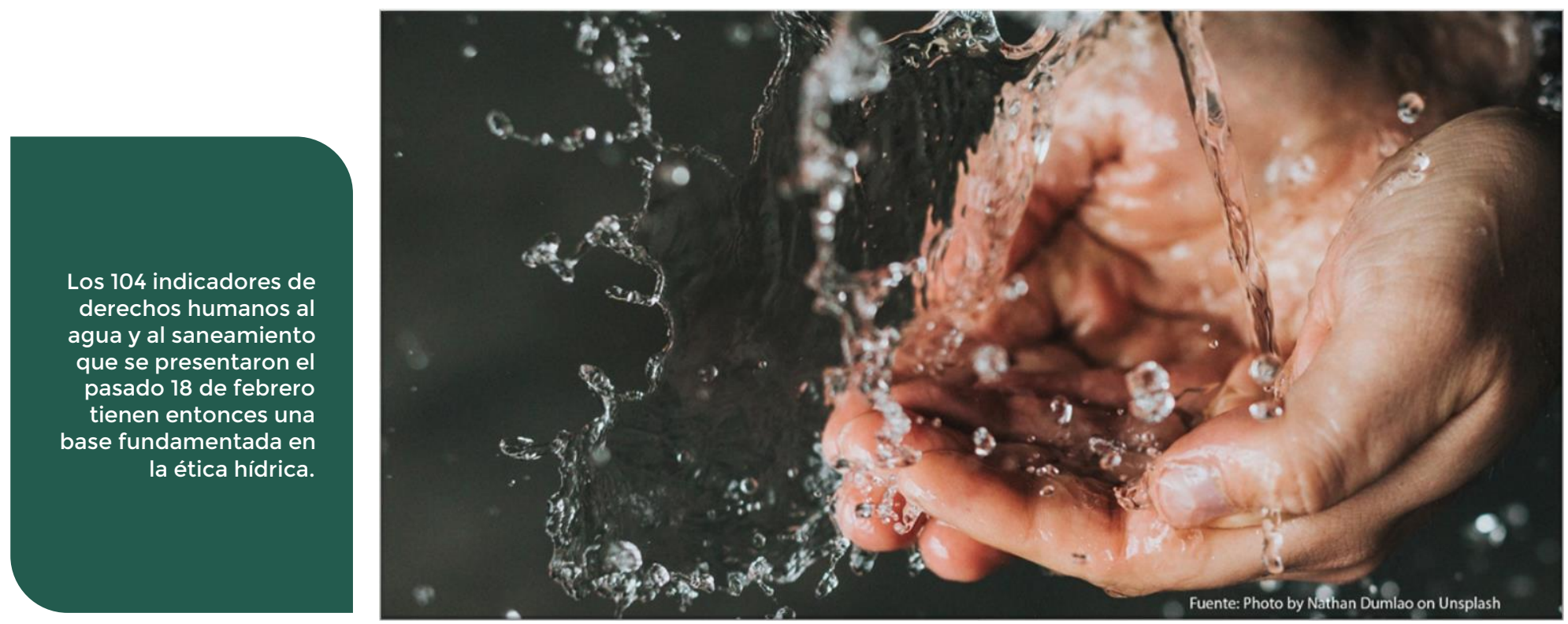

Al hablar de cumplimiento de derechos humanos, la distancia entre su goce pleno o su realización efectiva y la emisión de normas o leyes que los reconocen es muy amplia e implica, por lo general, un proceso largo, lento y complejo.

En este camino, uno de los elementos fundamentales para la formulación, implementación, evaluación y seguimiento de las políticas públicas que lleven a su concreción es el conjunto de indicadores que sirven de hoja de ruta para el establecimiento de metas, la priorización de poblaciones y, en general, para la toma de decisiones.

Esta reflexión fue la que nos motivó a emprender el reto de formular un conjunto de indicadores de derechos humanos al agua y al saneamiento, de forma tal que le permitiera a instituciones del sector público, investigadores, organizaciones de la sociedad civil y a la ciudadanía en general, contar con información certera respecto a su nivel de cumplimiento y, por tanto, del bienestar de la población que es, en última instancia, el eje central de cualquier política pública y el sentido de los tratados internacionales en la materia.

Su elaboración partió de dos metodologías: la de la Oficina del Alto Comisionado de las Naciones Unidas para los Derechos Humanos (ONU-DH), que busca medir el cumplimiento de los derechos y que comprende los siguientes mecanismos de medición en materia de derechos humanos: en primer lugar, el compromiso del Estado para dar cumplimiento a las normas de derechos humanos; en segundo, los esfuerzos emprendidos por el Estado para cumplir estas obligaciones y, por último, los resultados de las iniciativas emprendidas por el Estado a lo largo del tiempo. Lo anterior se ha concretado en la 
configuración de indicadores de tres tipos respectivamente: estructurales, de proceso y de resultados, que fueron considerados para cada uno de los criterios normativos de los derechos: disponibilidad, calidad, aceptabilidad, accesibilidad y asequibilidad.

Respecto a estos últimos, vale la pena destacar que existen numerosas discusiones y un nivel elevado de consenso alrededor de sus definiciones conceptuales; sin embargo, frente a su definición operacional no hay tanta certeza aún, pues depende de múltiples factores culturales, geográficos y naturales, lo que complejiza aún más su medición.

La segunda metodología considerada fue la de la Organización de Estados Americanos (OEA), que ordena los indicadores en tres categorías conceptuales y tres principios transversales, con la intención de medir los avances en un aspecto específico y proporcionar información sobre los retos en la materialización del derecho en una esfera precisa de análisis. Cabe recordar que esta metodología es de cumplimiento obligatorio para los Estados partes, y se aplica para la medición y reporte de los derechos económicos, sociales y culturales (DESCAS). Las categorías conceptuales de esta metodología responden a los distintos aspectos en los que se debe reflejar el avance en la garantía y la protección de los derechos, y los principios transversales permiten identificar los mecanismos y políticas necesarios para asegurarlos, tendiendo como marco la protección igualitaria y no discriminatoria de los derechos; su adecuado nivel de información, participación, transparencia y rendición de cuentas; así como la evaluación de los recursos para el apropiado acceso a la justicia, que incluye la posibilidad de acceso a mecanismos de reclamo y protección.

Con estos dos antecedentes se creó una estructura que incorpora las dos metodologías y que retoma indicadores ya aceptados, como algunos del objetivo de desarrollo sostenible 6 de la Agenda 2030, algunos que miden el derecho a un medio ambiente sano y a la salud, entre otros. Este cruce de metodologías y de información permitió identificar vacíos y formular indicadores específicos que dieran cuenta de dichos vacíos y que respetaran, además, los principios ya enunciados. Como resultado de todo ello, y después de una consulta nacional con más de 200 personas relacionadas con el tema, se obtuvieron 104 indicadores distribuidos de la siguiente forma:

Tabla 1. Orden matricial de los Indicadores de derechos humanos al agua y al saneamiento

\begin{tabular}{|c|c|c|}
\hline Estructurales & Proceso & \multicolumn{2}{c|}{ Resultados } \\
\hline \multicolumn{2}{|c|}{ Recepción del derecho $(n=29)$} \\
\hline 10 & 7 & 12 \\
\hline Contexto financiero y compromiso presupuestal $(n=9)$ \\
\hline \multicolumn{3}{|c|}{ Capacidades estatales $(n=28)$} \\
\hline 6 & 16 & 3 \\
\hline Igualdad y no discriminación $(n=12)$ \\
\hline 2 & 8 & 2 \\
\hline Acceso a información y participación $(n=11)$
\end{tabular}




\begin{tabular}{|c|c|c|c|}
\hline 7 & 3 & 1 \\
\hline & Acceso a la justicia $(n=15)$ & \\
\hline 1 & 10 & 4 \\
\hline 26 & & 50 & 28 \\
\hline
\end{tabular}

Una vez consolidado el total de indicadores, se diseñó una ficha descriptiva en la que, de nuevo, se consideraron los principios generales a considerar y aquellos aspectos que permitieran visibilizar diferencias y aportar elementos para una mejor toma de decisiones. En ese sentido, la elaboración y resultado de este conjunto de indicadores tiene un compromiso claro con la justicia hídrica y un profundo apego al compromiso de no dejar a nadie atrás, por lo que se hace énfasis en evidenciar la situación real de la población en términos de cumplimiento de derechos humanos al agua y al saneamiento, teniendo muy presente su relación profunda con el cumplimiento de otros derechos (vida, salud, alimentación, medio ambiente sano, entre otros) y por tanto con la dignidad humana, que son, en última instancia, la materialización de los principios de la ética hídrica que rigen nuestra gestión.

Toda esta información precisa por regiones y localidades, poblaciones específicas, dimensiones de los derechos, nivel de cumplimiento y demás elementos de las fichas descriptivas hará posible la visibilización de las particularidades a las que se deben orientar los esfuerzos para dar cumplimiento cabal a los compromisos adquiridos internacionalmente y, en particular, a los suscritos en la Agenda 2030 y el Acuerdo de Escazú.

Los 104 indicadores de derechos humanos al agua y al saneamiento que se presentaron el pasado 18 de febrero tienen entonces una base fundamentada en la ética hídrica, y son producto del trabajo transdisciplinar y colectivo entre diversos actores que aportaron, desde su ejercicio profesional, vivencia personal, conocimiento empírico, especialidad académica, etc. su esfuerzo y conocimiento para la concreción de los mismos, y van a permitir contar con una línea base para estos derechos; cumplir con las obligaciones del Estado en el reporte de avances; visibilizar la situación de poblaciones específicas en cuanto al cumplimiento de estos derechos en el país; contar con datos para la formulación de metas y para la toma de decisiones; identificar áreas de oportunidad y determinar prioridades en la atención; impulsar el acceso a información, la transparencia, la rendición de cuentas y la participación en materia de DD. HH.; fortalecer capacidades regionalmente mediante la transferencia de metodologías para el diseño de indicadores y de la experiencia nacional en su implementación; y, en última instancia, acercarnos cada vez más a la justicia hídrica que implica su concreción.

Para finalizar, retomaremos algunas de las ideas principales de la presentación:

“Agradecemos el esfuerzo voluntario y proactivo del IMTA de construirlos (los indicadores) y ponerse a la altura (del sistema). Esperamos que sea un referente para otras instituciones" Dr. Cristopher Ballinas, director general de Derechos Humanos y Democracia, Secretaría de Relaciones Exteriores.

"Es la primera vez que una instancia pública con un mandato en materia de derechos económicos, sociales, culturales y ambientales, logra el resultado que hoy tenemos, (...) en ese sentido, el IMTA es pionero y un gran ejemplo a seguir". (...) "El producto que van a tener en sus manos se ha desarrollado siguiendo los más altos estándares metodológicos internacionales y cuenta con una validación y retroalimentación de más de 200 actores nacionales, (...) lo que sin lugar a duda ha sido un amplísimo proceso de consulta. El producto final es una auténtica joya en términos de indicadores, porque cubre los vacíos de metodologías previas y sienta las bases para la medición de los DD. HH. al agua y al 
saneamiento tanto en México como en otros países" Mtro. Jesús Peña Palacios, representante adjunto en México de la Alta Comisionada de las Naciones Unidas para los DD. HH., Oficina del Alto Comisionado de las Naciones Unidas para los DD. HH. en México.

“Su implementación (de los indicadores) nos va a permitir fomentar la riqueza de la vida humana y las posibilidades existenciales de las personas, antes que la riqueza de la economía en la que viven los seres humanos, poniendo énfasis en las personas y el territorio, pavimentando de esta manera el camino hacia un mundo en el que cada persona pueda vivir una existencia caracterizada por tres elementos: dignidad, oportunidad y comunidad, y donde todos podamos hacerlo conforme a los elementos de la casa, nuestra tierra". Dr. Adrián Pedrozo Acuña, director general del Instituto Mexicano de Tecnología del Agua.

A manera de cierre, les invitamos a consultar los indicadores de derechos humanos y sus fichas técnicas, alojados en la página institucional del IMTA (https://bit.ly/IndicadoresDDHH) desde donde, en un ejercicio proactivo de acceso a la información, están publicados y listos para ser descargados. Esperamos que sean consultados, difundidos y apropiados por todas las personas interesadas. Por nuestra parte continuaremos el esfuerzo por hacer de ellos una herramienta útil para la toma de decisiones de forma que nos acerquemos cada vez más a la meta universal de no dejar a nadie atrás.

A continuación, dejamos para su consulta los videos de los eventos realizados al respecto:

Los derechos humanos al agua y al saneamiento en México: lanzamiento de los indicadores para su medición, realizado el 18 de febrero de 2022 https://youtu.be/TqCatDxka6I

Conversatorio sobre la importancia de los DD. HH. a partir de indicadores: explicación de la metodología

y la importancia de los resultados, realizado el 10 de diciembre de 2021: https://youtu.be/bJNDCs4w5 s 